\title{
Opiate Withdrawal and the Rat Locus Coeruleus: Behavioral, Electrophysiological, and Biochemical Correlates
}

\author{
Kurt Rasmussen, ${ }^{a}$ Dana B. Beitner-Johnson, John H. Krystal, George K. Aghajanian, and Eric J. Nestler \\ Laboratory of Molecular Psychiatry, Departments of Psychiatry and Pharmacology, Yale University School of Medicine \\ and Connecticut Mental Health Center, Now Haven, Connecticut 06508
}

\begin{abstract}
We have compared the time course of the behavioral manifestations of opiate withdrawal to the in vivo activity of locus coeruleus (LC) neurons and to increases in the levels of G-proteins, adenylate cyclase, and cAMP-dependent protein kinase known to occur in the LC in opiate-dependent animals. Rats were given morphine by daily subcutaneous implantation of morphine pellets for $5 \mathrm{~d}$. On the sixth day, morphine withdrawal was induced by subcutaneous administration of naltrexone, an opiate receptor antagonist, with additional doses given 6 and $24 \mathrm{hr}$ later, conditions that resulted in sustained, maximal levels of withdrawal over the duration of the experiment. We found a striking parallel between the time courses of the behavioral signs and the increased activity of LC neurons during withdrawal, both of which appeared to follow 2 phases. There was an early, rapid phase, during which withdrawal signs and increased LC activity became most pronounced within 15-30 min after naltrexone administration, and then recovered rapidly by over $50 \%$ within $4 \mathrm{hr}$ of withdrawal. Subsequently, there was a slower phase, during which the persisting withdrawal signs and elevated LC activity remained roughly constant from 4 to $24 \mathrm{hr}$ and did not recover completely until after $72 \mathrm{hr}$ of continuous withdrawal. Adenylate cyclase and CAMP-dependent protein kinase activities in isolated LC subcellular fractions, both elevated in dependent animals, recovered to control levels after $6 \mathrm{hr}$ of withdrawal, in parallel with the rapid phase of withdrawal. Levels of $G_{i}$ and $G_{o}$, also elevated in dependent animals, remained only slightly elevated at 6 $\mathrm{hr}$ and returned to normal by $24 \mathrm{hr}$. Taken together, these data suggest that increased neuronal activity in the LC is associated temporally with the behavioral morphine withdrawal syndrome and that increased levels of G-proteins and an up-regulated CAMP system may contribute to the early withdrawal activation of these neurons.
\end{abstract}

The brain noradrenergic system has been hypothesized to play an important role in opiate dependence and withdrawal (see Redmond and Krystal, 1984). Studies of opiate regulation of the noradrenergic system have focused on the locus coeruleus

\footnotetext{
Received Jan. 16, 1990; revised March 7, 1990; accepted March 13, 1990.

This work was supported by U.S. P.H.S. Grant DA-05490 (to E.J.N.) and Yale program project Grants 2 P01 MH 25642 and 5 P50 DA 04060, and by the Abraham Ribicoff Research Facilities of the Connecticut Mental Health Center. State of Connecticut Department of Mental Health.

Correspondence should be addressed to Dr. Eric J. Nestler at the above address.

a Present address: Lilly Research Labs, Lilly Corporate Center, Indianapolis, IN 46285 .

Copyright (C) 1990 Society for Neuroscience $0270-6474 / 90 / 072308-10 \$ 03.00 / 0$
}

(LC), the largest cluster of noradrenergic neurons in the brain (Dahlstrom and Fuxe, 1965; Foote et al., 1983). This nucleus possesses a high density of opiate receptors, particularly of the $\mu$ and $\kappa$ subtype (Tempel and Zukin, 1987). In anesthetized or awake rats, local or systemic administration of opiates results in the inhibition of LC neuronal firing rates (Korf et al., 1974; Bird and Kuhar, 1977; Aghajanian, 1978; Valentino and Wehby, 1988). In awake cats, local, but not systemic, administration of opiates decreases the activity of LC neurons (Rasmussen and Jacobs, 1985; Abercrombie et al., 1988). Tolerance develops to this inhibitory effect of opiates, as LC firing rates return toward control levels with chronic opiate administration (Aghajanian, 1978). LC neurons also exhibit dependence after chronic opiate exposure, as administration of opiate receptor antagonists to opiate-dependent rats results in increased LC firing rates in vivo (Aghajanian, 1978; Rasmussen and Aghajanian, 1989; Valentino and Wehby, 1989). It has been proposed that this withdrawal-induced activation of LC neurons plays a role in some of the behavioral manifestations of the opiate abstinence syndrome seen in animals and humans (see Redmond and Krystal, 1984; and Discussion).

The mechanisms underlying the acute inhibition of $\mathrm{LC}$ neurons by opiates have been examined with electrophysiological and biochemical techniques. Intracellular recordings in vitro have suggested that acute opiate inhibition of LC neurons involves regulation of 2 types of ion channels: activation of a potassium channel and inhibition of a slowly depolarizing sodium channel (Aghajanian and Wang, 1987; North et al., 1987; Wang and Aghajanian, 1987). Opiate regulation of both channels is mediated through pertussis toxin-sensitive G-proteins (Aghajanian and Wang, 1986; North et al., 1987), and opiate regulation of the slowly depolarizing sodium channel may be mediated through an opiate/G-protein-induced decrease in neuronal cAMP levels (Aghajanian and Wang, 1987; Wang and Aghajanian, 1987). Biochemical studies have demonstrated that, acutely, opiates inhibit adenylate cyclase activity in the $\mathrm{LC}$, an effect mediated through a pertussis toxin-sensitive G-protein(s) (Duman et al., 1988; Beitner et al., 1989), and decrease cAMP-dependent protein phosphorylation in this brain region (Guitart and Nestler, 1989). Presumably, opiate-induced decreases in cAMP-dependent protein phosphorylation lead, either directly or indirectly, to alterations in the conductance of the slowly depolarizing sodium channel as well as to additional actions of opiates in LC neurons.

The mechanisms underlying opiate tolerance, dependence, and withdrawal in LC neurons have also been examined with a variety of techniques. Autoradiographic and electrophysiolog- 
ical studies have failed to find alterations in opiate receptors or opiate-regulated ion channels in the $\mathrm{LC}$ in response to chronic opiate administration (see Redmond and Krystal, 1984; Christie et al., 1987; Loh et al., 1988), although it is possible that subpopulations of opiate receptors in the LC may be altered by chronic opiates as reported for other brain regions (Danks et al., 1988). Nevertheless, these results raise the possibility that opiate tolerance and dependence in the LC may be subserved by steps between opiate receptors and ion channels, namely, intracellular messengers such as G-proteins and the cAMP system. Indeed, chronic opiate administration has been shown to up-regulate the G-protein/cAMP system at each major step between receptor and physiological response. Chronic, but not acute, opiates have been shown to increase levels of $G_{i \alpha}$ and $\mathrm{G}_{\mathrm{o} \alpha}$, adenylatc cyclasc activity, cAMP-dependent protein kinase activity, and a number of morphine- and cAMP-regulated phosphoproteins (MARPPs) in the LC, effects not observed in several other brain regions studied (Duman et al., 1988; Nestler and Tallman, 1988; Guitart and Nestler, 1989, 1990; Nestler et al., 1989; Guitart et al., 1990). It has been proposed that such an up-regulated G-protein/cAMP system contributes to opiate tolerance, dependence, and/or withdrawal in the LC (Nestler, 1990).

The present study represents a series of behavioral, electrophysiological, and biochemical studies, conducted in parallel, designed to evaluate the activity of the G-protein/cAMP system during opiate withdrawal, and to relate such intracellular changes to alterations in LC neuronal activity during withdrawal and to the appearance of behaviors associated with the opiate abstinence syndrome. The results support the view that withdrawal activation of LC neurons is associated with behavioral withdrawal, and that an up-regulated G-protein/cAMP system contributes to the withdrawal activation of LC neurons.

\section{Materials and Methods}

In vivo drug treatments. Male Sprague-Dawley rats (initial weight 200 gm) were used in these studies. Under light halothane anesthesia, morphine pellets (containing $75 \mathrm{mg}$ of morphine base; National Institute on Drug Abuse) were implanted subcutaneously daily for $5 \mathrm{~d}$. This treatment protocol represents moderate levels of chronic morphine administration compared to previous studies (see Blasig et al., 1973; Aghajanian, 1978; Christie et al., 1987). Control rats either received no treatment or received identical anesthesia and surgery with the implantation of placebo pellets (National Institute on Drug Abuse); the 2 types of controls did not differ in subsequent behavioral, electrophysiological, and biochemical determinations. On the sixth day, $24 \mathrm{hr}$ after the last pellet implantation, the 2 most recent pellets were removed from the rats under light halothane anesthesia. Two hours later, opiate withdrawal was precipitated by subcutaneous administration of naltrexone $\mathrm{HCl}(100$ $\mathrm{mg} / \mathrm{kg}$; Dupont and Sigma). The same naltrexone dose was repeated 6 , 24 , and $72 \mathrm{hr}$ after the initial dose of naltrexone. This paradigm of opiate withdrawal $(5 \mathrm{~d}$ of morphine treatment, removal of the 2 most recent morphine pellets on day 6 , naltrexone precipitation of opiate withdrawal $2 \mathrm{hr}$ later followed by subsequent doses of naltrexone at 6 , 24 , and $72 \mathrm{hr}$ ) was followed for all behavioral, electrophysiological, and biochemical experiments.

Comments on the opiate withdrawal protocol used. The dose of naltrexone used in these studies was chosen on the basis of preliminary studies, the goal of which was to determine the lowest dose of naltrexone that would result in sustained, maximal levels of withdrawal from the initiation of withdrawal to the complete resolution of opiate dependence. Although lower doses of naltrexone $(1,10$, or $50 \mathrm{mg} / \mathrm{kg})$ precipitated considerable behavioral signs of withdrawal, as reported by numerous laboratories, the withdrawal behaviors resolved completely within 2-6 $\mathrm{hr}$, with a repeat dose of naltrexone at $6 \mathrm{hr}$ still precipitating considerable levels of withdrawal. These results indicated that these doses of naltrexone did not result in sustained, maximal withdrawal, possibly due to the high tissue levels of morphine remaining in the animals (Blasig et al., 1973; Misra, 1978) and to the fact that a large majority of sys- temically administered naltrexone is eliminated rapidly in the urine (see Lee et al., 1988). In contrast, administration of $100 \mathrm{mg} / \mathrm{kg}$ of naltrexone resulted in the same peak levels of opiate withdrawal initially, but the withdrawal symptoms persisted beyond $6 \mathrm{hr}$, at which time an additional dose of naltrexone produced no further increase in withdrawal symptoms. These results indicated that this higher dose of naltrexone was sufficient to produce sustained, maximal withdrawal through $6 \mathrm{hr}$. Similar studies demonstrated that additional naltrexone doses at 6 and $24 \mathrm{hr}$ after the initial dose were required to produce sustained levels of withdrawal over the course of experimentation, which lasted $72 \mathrm{hr}$. Administration of a fourth naltrexone dose at $72 \mathrm{hr}$ was found to have no effect on the animals behaviorally or electrophysiologically, indicating that opiate dependence had resolved completely at this time. It is important to note that removal of the 2 most recent morphine pellets was necessary to enable the precipitation of sustained, maximlal withdrawal with this dose of naltrexone. Removal of the earlier pellets did not affect the dose of naltrexone required, consistent with the finding that the output of morphine by the pellets is essentially complete after 3-4 d (Blasig et al., 1973). Finally, removal of the 2 most recent pellets, without administration of naltrexone, did not lead to significant behavioral signs of opiate withdrawal over the entire $72 \mathrm{hr}$ course of the study. Subsequently, administration of naltrexone at $72 \mathrm{hr}$ was found to produce considerable levels of withdrawal, about $75 \%$ of that observed in animals that received the naltrexone $2 \mathrm{hr}$ after removal of the pellets. These results indicate some spontaneous withdrawal had occurrcd ovcr the $72 \mathrm{hr}$ period, but that most of the dependence persisted over this time period, possibly due to the very long half-life of morphine in the brain (Misra, 1978).

Behavioral assessment of opiate withdrawal. The severity and linte course of opiate withdrawal was studied in rats treated with morphine and naltrexone as discussed above. Animals were studied in pairs in clear Plexiglas cages $(11$ in. $\times 7$ in. $\times 5$ in. $)$ and remained in these cages for the entire study. Animals were adapted to the cages for $30 \mathrm{~min}$, after which the animals were rated for 15 min to assess the presence of any baseline "abstinence-like" behaviors. Opiate withdrawal was then assessed continuously for $1 \mathrm{hr}$ following the initial naltrexone injection and again for 15 min periods at $1.5,2,3,4,5$, and $6 \mathrm{hr}$ after naltrexone administration. Animals received a second dose of naltrexone at $6 \mathrm{hr}$ and were rated for $1 \mathrm{hr}$ thereafter. Following this rating period, food and water were made available in the testing cages. $\Lambda t 24$ and $72 \mathrm{hr}$, animals were rated for $15 \mathrm{~min}$ prior to the third and fourth doses of naltrexone and for $30 \mathrm{~min}$ after naltrexone administration.

Fourteen previously identified behaviors characteristic of the rat opiate abstinence syndrome were assessed in this study (see Himmelsbach et al., 1935; Way et al., 1969; Blasig et al., 1973; Wei, 1973; Aceto et al., 1986). The absolute frequency of 7 episodic behaviors was recorded and an additional score was calculated based on multiples of 5 incidents $(0=$ no incidents; $1=1-5$ incidents; $2=6-10$ incidents; and $3=>11$ incidents). Behaviors scored in this manner included: irritability (defined as episodes of conflict-induced vocalization), jumping, wet dog shakes, writhing (or abdominal stretching), stereotyped head bobbing, sweeping tail movements, and yawning. Two behaviors were similarly scored from 0 to 3 by multiples of 10 occurrences; these included discrete episodes of teeth chatter (scparatcd by at least $3 \mathrm{sec}$ ) and chewing (without any matter in the mouth). Five withdrawal behaviors could not be defined in discrete episodes, and the severity of these behaviors was assessed using predefined anchor points on a 4 point scale: $0=$ absent; $1=$ mild; 2 = moderate; $3=$ marked. Behaviors rated in this fashion were lacrimation, piloerection, ptosis, salivation, and diarrhea. Behavioral data were analyzed in 15 min epochs. For the purposes of comparison with other aspects of this study, using previous withdrawal scales as a guide (Wei, 1973; Aceto et al., 1986), a composite score of withdrawal severity was calculated using the criteria described above, ranging from 0 (no withdrawal behaviors) to a maximum possible score of 42 (14 behaviors $\times 3$ ). Raw composite scores are reported in this study; baseline scores, which were $\leq 1$ for all animals studied, were not subtracted from subsequent scores. The magnitude of weight loss was also determined in somc animals at basclinc and at 3,6,24, and $72 \mathrm{hr}$ of withdrawal, but was not included in overall withdrawal ratings.

Electrophysiological recordings from $L C$ neurons. The firing rate of LC neurons was studied by single unit recording techniques. Control and morphine-treated animals were anesthetized with intraperitoneal chloral hydrate $(400 \mathrm{mg} / \mathrm{kg})$; supplemental doses of anesthetic were administered through a lateral tail vein as needed. Body temperature was maintained at $35-37^{\circ} \mathrm{C}$ by a heating pad. Rats were mounted in a 
stereotaxic apparatus and a cisternal drainage was performed to help prevent tissue swelling. A burr hole was made $1.2 \mathrm{~mm}$ posterior to lambda and $1.1 \mathrm{~mm}$ lateral to the midline. The recording electrodes were single-barrel glass micropipettes, broken back to a tip diameter of $2-3 \mu \mathrm{m}$, and filled with a $2 \mathrm{M} \mathrm{NaCl}$ solution containing $2 \%$ pontamine sky blue. Procedures for locating the LC and for extracellular singleunit recordings were as described previously (Aghajanian et al., 1977). For histological confirmation of LC recording sites, the electrode tip locations were marked with a dye spot at the end of each experiment by passing negative current through the electrodes.

For a group of 2 control and 4 morphine-treated rats, LC unit activity was sampled for $15 \mathrm{~min}$ before and continuously for $1 \mathrm{hr}$ after the initial injection of naltrexone, and then for $15 \mathrm{~min}$ periods at $2,3,4,5$, and $6 \mathrm{hr}$ postinjection. Animals received a second dose of naltrexone at 6 $\mathrm{hr}$, and LC unit activity was sampled for $30 \mathrm{~min}$ following the injection. A separate group of 2 control and 2 morphine-treated animals received initial doses of naltrexone and repeat doses $6 \mathrm{hr}$ later while they were awake. At $24 \mathrm{hr}$, the animals were anesthetized and LC unit activity studied electrophysiologically for $30 \mathrm{~min}$ both before and after a third naltrexone dose. Similarly, LC unit activity was assessed at $72 \mathrm{hr}$ after withdrawal in a group of 2 control and 2 morphine-treated animals that received their first 3 doses of naltrexone (at times 0,6 , and $24 \mathrm{hr}$ ) while awake. In all experiments, the firing rate of 4-6 separate LC neurons was assessed during each $15 \mathrm{~min}$ recording period. Recordings of stable firing rates were obtained from each neuron for at least 2-3 min.

Adenylate cyclase and cAMP-dependent protein kinase assays. Animals were killed by decapitation 20 min or $1,2,6,24$, or $72 \mathrm{hr}$ after the precipitation of opiate withdrawal. Animals killed at 6,24 , and 72 hr were killed just prior to the additional naltrexone injections that would normally be scheduled at these time points. Isolated brains were cooled immediately in ice-cold physiological saline, and LC nuclei were excised from $0.75 \mathrm{~mm}$ thick coronal cross-sections of brain stem by use of a 15-gauge syringe needle as described (see Nestler and Tallman, 1988). Each pair of LC punches obtained from individual rats was pooled and used for further analysis. LC punches contained similar amounts of protein, determined by the method of Lowry et al. (1951); data were therefore expressed "per punch" rather than "per mg protein." (Note: In most experiments, aliquots of the same brain samples were analyzed for adenylate cyclase, cAMP-dependent protein kinase, and G-proteins; in some experiments, different animals were used for these various determinations.)

Isolated LC were homogenized in $0.1 \mathrm{ml}$ of ice-cold $50 \mathrm{~mm}$ Tris, $\mathrm{pH}$ 7.4/1 mm dithiothreitol/1 mM EGTA/10 $\mu \mathrm{g}$ per ml leupeptin $/ 50$ kallikrein units per $\mathrm{ml}$ aprotinin. For adenylate cyclase assays, aliquots of the homogenates were centrifuged at $10,000 \times \mathrm{g}$ for $15 \mathrm{~min}$ in a Savant microfuge at $4^{\circ} \mathrm{C}$ and pellets were resuspended in 2.5 times the original volume of $10 \mathrm{~mm}$ Tris, $\mathrm{pH} 7.4$. Adenylate cyclase assays were then performed under basal conditions and in the presence of GTP $(100$ $\mu \mathrm{M})$ and forskolin $(5 \mu \mathrm{M})$ exactly as described (Duman et al., 1988). The specific activity of adenylate cyclase in LC from control animals under basal and forskolin-stimulated conditions was $\sim 40$ and $\sim 180 \mathrm{pmol} /$ $\mathrm{min} / \mathrm{mg}$ protein, respectively, similar to values reported previously (Duman et al., 1988).

For protein kinase assays, aliquots of LC homogenates were centrifuged in a Beckman airfuge at $150,000 \times \mathrm{g}$ for $10 \mathrm{~min}$ at $4^{\circ} \mathrm{C}$. The supernatants were designated the soluble fractions; the pellets were resuspended in the original volume of homogenization buffer and were designated the particulate fractions. Duplicate aliquots of the fractions were assayed for cAMP-dependent protein kinase activity by use of a filter paper assay using purified histone as substrate exactly as described (Nestler and Tallman, 1988). cAMP-dependent protein kinase activity was calculated as the difference in histone phosphorylation observed in the presence of cAMP and protein kinase inhibitor, a specific inhibitor of cAMP-dependent protein kinase (see Nestler and Tallman, 1988). Under the assay conditions used, cAMP-dependent protein kinase activity was linear over a 5-fold range of tissue concentration and between 1 and $5 \mathrm{~min}$ of incubation. The specific activity of cAMP-dependent protein kinase was $\sim 150 \mathrm{pmol} / \mathrm{min} / \mathrm{mg}$ protein in both particulate and soluble fractions of LC from control animals, similar to values reported previously (Nestler and Tallman, 1988).

$A D P$-ribosylation of $G$-proleins. LC homogenates were centrifuged at $10,000 \times g$ for $15 \mathrm{~min}$ in a microfuge and the pellets resuspended in the original volume of $100 \mathrm{~mm}$ Tris, $\mathrm{pH} 8 / 10 \mathrm{~mm}$ thymidine $/ 10 \mathrm{~mm}$ isoniazide $/ 5 \mathrm{mM} \mathrm{MgCl}_{2} / 2.8 \mathrm{~mm}$ dithiothreitol $/ 2.4 \mathrm{~mm}$ benzamidine $/ 0.8$ mM EDTA $/ 2.5 \mathrm{~mm} \mathrm{ATP} / 2 \mathrm{mM}$ GTP $/ 4 \%$ sucrose $/ 0.8 \mu \mathrm{g} / \mathrm{ml}$ soybean trypsin inhibitor $/ 0.5 \%$ triton X-100. Duplicate aliquots of resuspended pellets were subjected to ADP-ribosylation exactly as described (Nestler et al., 1989), except that ribosylation reactions were terminated by the addition of (final concentration) $10 \%$ trichloroacetic acid, which dramatically improved the recovery of the ADP-ribosylated G-proteins in the final reaction pellets. The pellets were then prepared for, and analyzed by, SDS-PAGE (with $9 \%$ acrylamide $/ 0.25 \%$ bisacrylamide in the resolving gels) as described (Nestler et al., 1989). ADP-ribosylated $\mathrm{G}$-protein bands were identified by autoradiography and levels of ADP. ribosylation were quantitated with a Betagen Betascope analyzer or by excising individual bands from dried gels and counting them by liquid scintillation. Under the assay conditions used, approximately 20-30 pmol of [32P]ADP-ribose were incorporated into $G_{i \alpha}+G_{o x}$ per mg of membrane protein. ADP-ribosylation levels were linear over a 3-fold range of tissue concentration and were $>85 \%$ of ADP-ribosylation levcls observed with higher NAD or toxin concentrations and longer incubation times.

\section{Results}

\section{Behavioral changes during opiate withdrawal}

Naltrexone, a long-acting opiate receptor antagonist, was administered to opiate-dependent rats according to a protocol that elicited sustained, maximal levels of opiate withdrawal for the duration of the experiment, as described in Materials and Methods. The resulting opiate abstinence syndrome was quantitated by use of a composite score of 14 behaviors (see Materials and Methods). Precipitation of opiate withdrawal by naltrexone resulted in a rapid and dramatic opiate abstinence syndrome that peaked within 15-30 min of naltrexone administration and did not resolve completely until $72 \mathrm{hr}$ of withdrawal. As shown in Figure 1, the time course of withdrawal suggests that there are 2 phases of the behavioral recovery from opiate abstinence using the protocol followed in this study. The first phase was rapid and lasted for about $4 \mathrm{hr}$, during which time there was a marked reduction in abstinence signs from a mean composite score of approximately 20 to about 6 (Fig. 1). The second phase was much slower: the severity of abstinence signs was roughly constant between 4 and $24 \mathrm{hr}$, with composite scores of 4-6, and recovered to control levels only after $72 \mathrm{hr}$ of continuous withdrawal. It should be emphasized that, as shown in Figure 1, rats showed no significant increase in withdrawal behaviors following repeat naltrexone doses at 6,24 , and $72 \mathrm{hr}$, supporting the view that the opiate withdrawal observed in this study represents sustained, maximal degrees of withdrawal (see Materials and Methods). In contrast to opiate-dependent rats, administration of naltrexone to control rats failed to induce significant abstinence behaviors during the entire course of experimentation, with composite withdrawal scores for control animals remaining below 1 (data not shown). In addition, it was found that precipitation of opiate withdrawal behaviors required prior treatment with chronic morphine: administration of naltrexone (100 $\mathrm{mg} / \mathrm{kg}) 30 \mathrm{~min}$ after acute morphine administration $(30 \mathrm{mg} / \mathrm{kg}$ subcutaneously) led to reversal of the acute sedative effects of morphine but to virtually no withdrawal signs, as reported for similar experiments previously (Blasig et al., 1973).

Although the composite scores of opiate withdrawal at the various time points studied showed a high level of consistency from rat to rat, there were significant differences in the specific behaviors exhibited by individual animals. The most distinctive withdrawal behaviors, such as jumping, wet dog shakes, writhing, and teeth chatter, showed the greatest rat-to-rat variability, whereas autonomic signs of withdrawal, such as piloerection, ptosis, salivation, and lacrimation, were similar among individual rats. Despite this individual variability, the various be- 

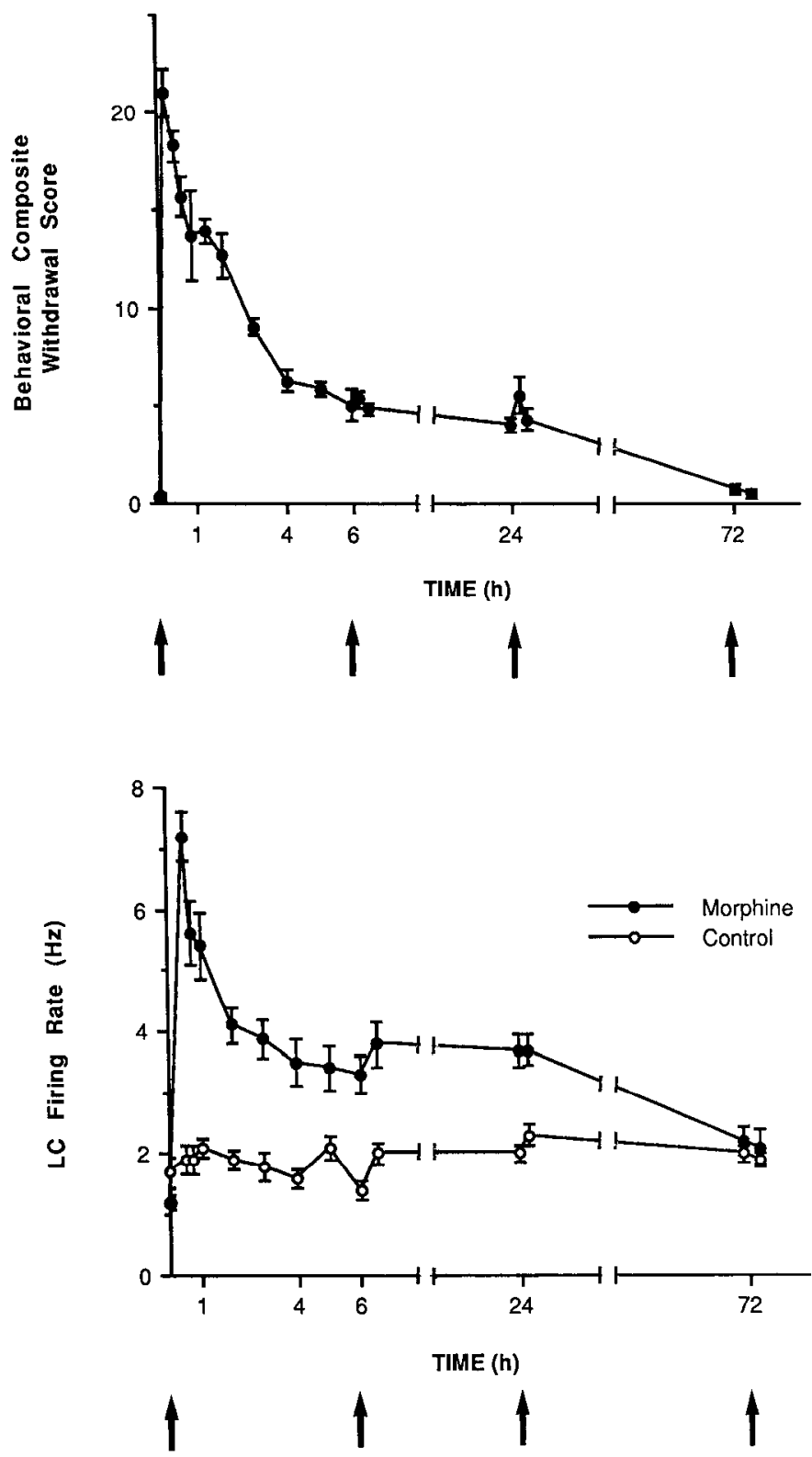

\section{Naltrexone}

Figure 1. Time course of abstinence behaviors and LC neuronal activity during opiate withdrawal. Rats were treated with morphine for 5 $\mathrm{d}$ and withdrawal was precipitated on day 6 by naltrexone administration. Naltrexone doses were repeated at 6,24 , and $72 \mathrm{hr}$ later. This protocol was shown to result in sustained, maximal levels of withdrawal (see Materials and Methods). Control animals received identical naltrexone injections. Top, The severity of the resulting opiate abstinence syndrome was studied by use of a composite score of 14 withdrawal behaviors, as described in Materials and Methods. The data represent means of composite scores \pm SEM of 6 animals at the $0-6 \mathrm{hr}$ time points and 4 animals at the 24 and $72 \mathrm{hr}$ time points. Behavioral withdrawal scores remained below 1 at all time points for the 6 control animals used in this study (not shown). Bottom, The firing rates of LC neurons during opiate withdrawal were studied by single-unit recording techniques, as described in Materials and Methods. The data represent mean firing rates \pm SEM of $10-40$ neurons at each time point from 24 control and morphine-treated rats (see Materials and Methods). Statistical analyses (analysis of variance scores and paired $t$-tests) of the behavioral and electrophysiological data revealed the following significant differences $(p<0.002)$. Behavioral scores and LC firing rates of withdrawing animals, at each of the time points between $15 \mathrm{~min}$ and $24 \mathrm{hr}$ of withdrawal, were significantly different from baseline, prenal- haviors seen during opiate withdrawal showed consistently different temporal characteristics. As shown in Table 1, some behaviors, such as jumping, were prominent in the early stages of withdrawal and absent in the later stages, whereas most of the other behaviors showed a much slower resolution. Moreover, whereas most behaviors reached maximal levels within the first $30 \mathrm{~min}$ of withdrawal, others, such as lacrimation, became maximal during later stages. Also shown in Table 1 is the weight loss sustained by the rats during the abstinence syndrome; maximal weight loss was seen at $24 \mathrm{hr}$, with most of the weight loss recovered by $72 \mathrm{hr}$.

\section{LC neuronal activity during opiate withdrawal}

The firing rate of LC neurons was studied before and during opiate withdrawal in anesthetized rats by use of single-unit recording techniques (see Materials and Methods). Just prior to the precipitation of withdrawal by naltrexone, the average firing rate of LC neurons was about $1.2 \mathrm{~Hz}$ (Fig. 1). This result indicates that chronic morphine treatment resulted in the development of substantial, though incomplete, levels of tolerance in these neurons: (1) the average firing rate of LC neurons in control rats was about $1.7 \mathrm{~Hz}$; (2) acute morphine is known to completely inhibit LC neuronal activity under these treatment conditions (see Aghajanian, 1978); and (3) the return of LC firing rates to $1.2 \mathrm{~Hz}$ occurs despite continuously high levels of morphine during the treatment period (see Blasig et al., 1973; Aghajanian, 1978).

Precipitation of opiate withdrawal by naltrexone resulted in a rapid and dramatic increase in LC neuronal activity (Fig. 1). An increase in LC firing rates was apparent within $3 \mathrm{~min}$ of naltrexone administration and peaked within the first 15-30 min when LC neuronal activity was elevated 6-fold over prenaltrexone levels and 4-fold over LC firing rates in control animals. LC neuronal activity did not recover completely until after 72 hr of withdrawal.

These results demonstrate clearly that the activation of LC neurons seen during withdrawal represents an overshoot of firing rates far above control levels and not merely a reversal of persistent opiate inhibition of the cells. Moreover, this overshoot is dependent on prior treatment with chronic morphinc: administration of opiate receptor antagonists following acute morphine administration has been shown previously to reverse the acute morphine inhibition of LC neurons, with LC firing rates returning to control levels but with no overshoot above control levels observed (Korf et al., 1974).

As shown in Figure 1, the time course of LC firing rates during opiate withdrawal suggests that there are 2 phases of the electrophysiological recovery of LC neurons from opiate abstinence. As observed with the behavioral signs of withdrawal, the first phase was rapid and lasted for $4 \mathrm{hr}$, during which time there was a marked reduction in LC firing rates from over $7 \mathrm{~Hz}$ to about $3.5 \mathrm{~Hz}$. The second phase was much slower: LC neuronal activity was roughly constant between 4 and $24 \mathrm{hr}$, with firing rates significantly above control at about $3.5 \mathrm{~Hz}$, and recovered

trexone scores (zero time point) and from control animals. In addition, the levels of peak behavioral symptoms and LC firing rates (i.e., at 15$30 \mathrm{~min}$ ) were significantly different from those observed at 4,6 , and 24 $\mathrm{hr}$. Finally, repeat naltrexone injections at 6,24 , and $72 \mathrm{hr}$ failed to elicit increases in behavioral symptoms or LC firing rates above their respective preinjection levels. 
Table 1. Temporal characteristics of some opiate abstinence behaviors

\begin{tabular}{llllll} 
& \multicolumn{5}{c}{ Time of withdrawal } \\
\cline { 2 - 6 } Behavior & $30 \mathrm{~min}$ & $3 \mathrm{hr}$ & $6 \mathrm{hr}$ & $24 \mathrm{hr}$ & $72 \mathrm{hr}$ \\
\hline Jumping $^{b}$ & $2.6 \pm 0.2(8)$ & $0(8)$ & $0(6)$ & $0(6)$ & $0(6)$ \\
Teeth chatter $^{t}$ & $2.3 \pm 0.3(8)$ & $1.5 \pm 0.3(8)$ & $1.0 \pm 0.3(6)$ & $0.2 \pm 0.1(6)$ & $0(6)$ \\
Salivation & $2.1 \pm 0.4(8)$ & $0.4 \pm 0.2(8)$ & $0(6)$ & $0(6)$ & $0(6)$ \\
Ptosis & $2.0 \pm 0.2(8)$ & $2.4 \pm 0.2(8)$ & $1.8 \pm 0.3(6)$ & $0.5 \pm 0.2(6)$ & $0(6)$ \\
Wet dog shakes & $1.1 \pm 0.2(8)$ & $1.4 \pm 0.2(8)$ & $0.7 \pm 0.2(6)$ & $1.0 \pm 0.2(6)$ & $0(6)$ \\
Lacrimation & $0(8)$ & $0.8 \pm 0.3(8)$ & $0(6)$ & $0(6)$ & $0(6)$ \\
Weight (\% decrease) & & $9.0 \pm 0.6(4)$ & $12.7 \pm 0.4(6)$ & $18.7 \pm 0.8(6)$ & $5.5 \pm 0.4(2)$
\end{tabular}

"The opiate withdrawal protocol and abstinence behaviors listed here are described in Materials and Methods. The values shown were calculated from scores of $0-3$ for each behavior (see Materials and Methods) and represent mean $\pm \operatorname{SEM}(n=$ number of animals).

${ }^{b}$ These behaviors showed the most rat-to-rat variability. For example, some animals exhibited prominent jumping and few wet dog shakes, whereas others exhibited the reverse pattern. As another example, although a relatively even temporal distribution is indicated for wet dog shakes, most animals exhibited them for discrete periods only, with some animals exhibiting them early in withdrawal and others later in withdrawal.

to control levels, with firing rates of about $2 \mathrm{~Hz}$, only after 72 hr of continuous withdrawal.

It should be noted that at 6,24 , and $72 \mathrm{hr}$, LC neurons showed no significant increase in their firing rates in response to repeat doses of naltrexone, again supporting the view that the opiate withdrawal observed in this study represents sustained, maximal degrees of withdrawal (see Materials and Methods). In contrast to opiate-dependent rats, administration of naltrexone to control rats failed to alter LC neuronal activity during the entire course of experimentation (see Fig. 1).

\section{Adenylate cyclase and cAMP-dependent protein kinase activities during opiate withdrawal}

Previous studies have shown that chronic, but not acute, treatment of rats with morphine results in $45 \%$ and $55-60 \%$ increases, respectively, in levels of adenylate cyclase activity and of soluble and particulate cAMP-dependent protein kinase activity in the LC (Duman et al., 1988; Nestler and Tallman, 1988). These increases in enzyme activity in dependent animals are shown by the zero time points in Figure 2. In order to assess the possible role of such elevated levels of enzyme activity in withdrawal activation of LC neurons, the level of these enzymes was studied during opiate withdrawal (Fig. 2). It was found that the activities of the 2 enzymes 20 min after the precipitation of withdrawal with naltrexone were indistinguishable from levels of the enzymes seen in LC of dependent animals that had not received naltrexone (and therefore were experiencing no withdrawal). Levels of both enzymes remained significantly elevated over control $1 \mathrm{hr}$ after initiation of withdrawal, at which time their activities were increased by 30-35\% compared to control. However, by $6 \mathrm{hr}$ of withdrawal, adenylate cyclase activity and soluble and particulate cAMP-dependent protein kinase activity had recovered to control levels. Protein kinase activity was also indistinguishable from control at 24 and $72 \mathrm{hr}$ of withdrawal. Interestingly, there appeared to be a consistent, but small $(<10 \%)$, decrease in adenylate cyclase activity at these later time points, but this effect never achieved statistical significance.

\section{$G$-protein ADP-ribosylation during opiate withdrawal}

Chronic, but not acute, treatment of rats with morphine also results in about a $40 \%$ increase in ADP-ribosylation levels of $\mathrm{G}_{\mathrm{i} \alpha}$ and $\mathrm{G}_{\alpha \alpha}$ in the LC (Nestler et al., 1989). This increase in
G-protein ADP-ribosylation in dependent animals is shown by the zero time point in Figure 3. In order to assess the possible role of such elevated levels in these G-proteins in withdrawal activation of LC neurons, G-protein ADP-ribosylation was studied during opiate withdrawal (Fig. 3). It was found that pertussis toxin-mediated ADP-ribosylation of $G_{i, x}$ and $G_{o \alpha}$ remained significantly elevated above control levels $1 \mathrm{hr}$ after the precipitation of opiate withdrawal with naltrexone, at which time G-protein levels showed a 35\% increase over control. At $6 \mathrm{hr}$, ADP-ribosylation levels were about 20\% elevated over control, but this effect, although consistent, was not statistically significant. ADP-ribosylation levels of $\mathrm{G}_{\mathrm{i} \alpha}$ and $\mathrm{G}_{\mathrm{o} \alpha}$ recovered completely to control levels by $24 \mathrm{hr}$ and remained at control levels at $72 \mathrm{hr}$ of continuous withdrawal.

\section{Discussion}

A striking parallel was observed in this study between the time course of the behavioral, electrophysiological, and aspects of the biochemical alterations that occur during antagonist-precipitated opiate withdrawal. The behavioral signs of opiatc withdrawal and increases in the firing rates of LC neurons showed virtually identical time courses. Both measures rose dramatically within minutes of naltrexone administration and showed increased levels for over $24 \mathrm{hr}$. Both measures peaked within 15-30 min, at which time LC firing rates were approximately 4-fold above the normal range for LC neurons. This is in contrast to acute studies, where opiate antagonists have been shown to reverse the acute morphine inhibition of LC neurons and bring their firing rates only back to control levels (Korf et al., 1974). Behavioral signs of withdrawal and elevated LC firing rates decreased rapidly from this early peak over the first 2-4 hr of withdrawal, then remained at relatively stable, elevated levels from 4 to $24 \mathrm{hr}$, and returned to baseline by $72 \mathrm{hr}$. The recovery from behavioral abstinence and $\mathrm{LC}$ withdrawal activation, therefore, appeared to follow 2 phases: an early, rapid phase, during which time $>50 \%$ of the behavioral and electrophysiological signs of withdrawal resolved, and a later, slower phase, during which time the remaining behavioral and electrophysiological signs of withdrawal required $72 \mathrm{hr}$ of continuous withdrawal for complete resolution.

The biochemical parameters measured in the $\mathrm{LC}$ appeared to correlate temporally with the early, rapid phase of withdrawal. 

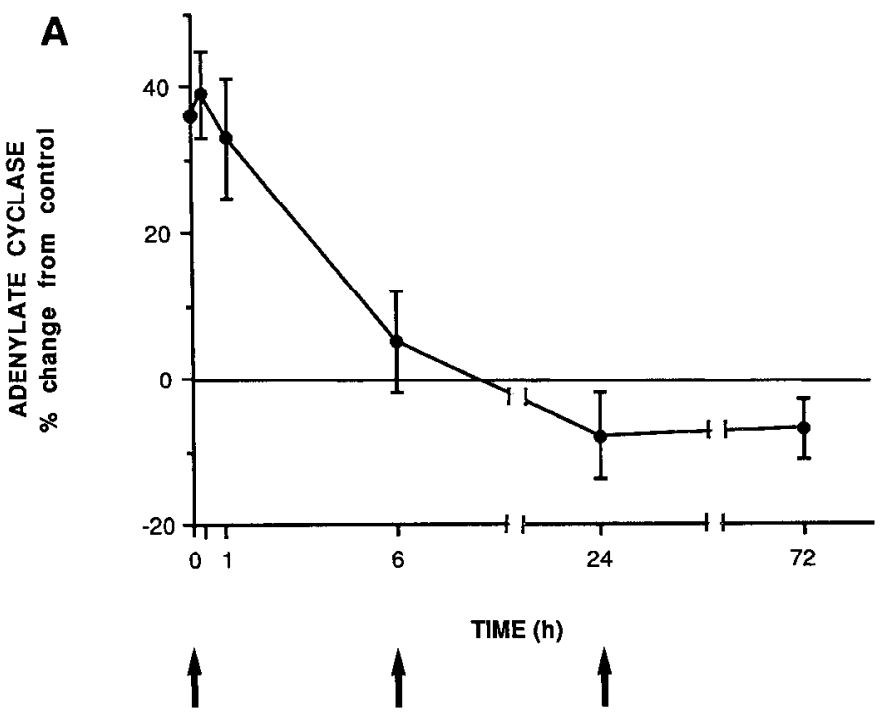

\section{Naltrexone}
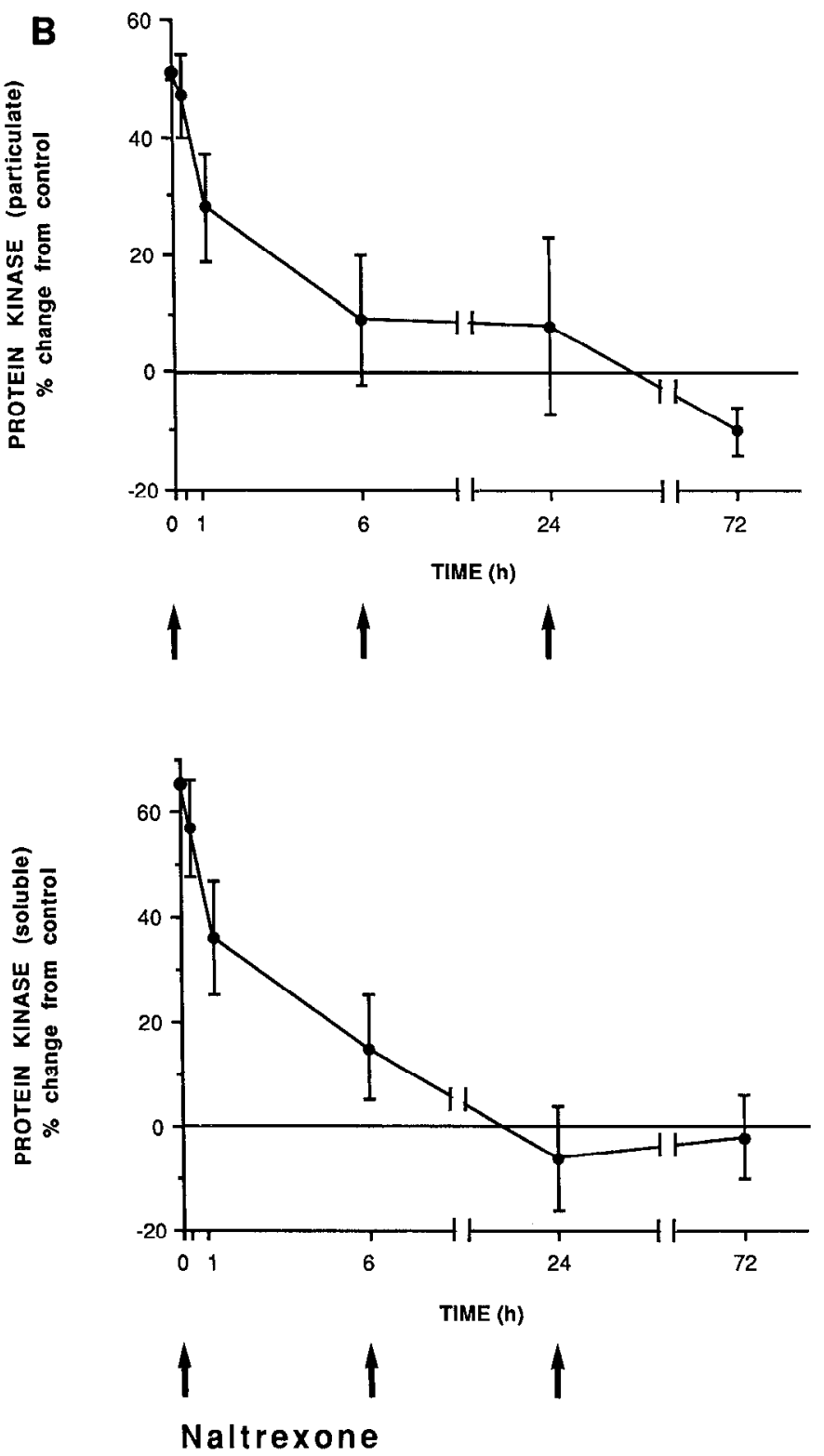

Thus, adenylate cyclase and cAMP-dependent protein kinase activities, both elevated in the LC of dependent animals, remained elevated at $20 \mathrm{~min}$, showed partial declines toward control levels (but remained significantly elevated) at $1 \mathrm{hr}$, and were back to control levels by $6 \mathrm{hr}$. A similar time course was seen for ADP-ribosylation levels of $G_{i \alpha}$ and $G_{o x}$, except that their recovery to control levels appeared to be somewhat slower with a partial, though not statistically significant, increase still observed at $6 \mathrm{hr}$. The rapid recovery of the G-proteins, adenylate cyclase activity, and cAMP-dependent protein kinase activity seen during withdrawal is particularly interesting in view of recent evidence that opiate-induced alterations in these proteins, where possible to study, involve increases at the messenger RNA and protein level (see Nestler et al., 1989; Nestler, 1990). This suggests that these proteins have high turnover rates in LC neurons. The results also underscore the rapidity with which changes in neuronal gene expression can occur in the brain and thereby account for a wide range of adaptive phenomena.

A major difference between the biochemical and the behavioral and electrophysiological parameters observed in this study is that the biochemical parameters are elevated in opiate-dependent animals prior to the preciptation of opiate withdrawal, whereas the behavioral and electrophysiological parameters become manifest only after the precipitation of withdrawal. Our working hypothesis, discussed further below, is that chronic morphine leads to increases in the G-protein/cAMP system in the LC that are revealed by in vitro assays, but that the functional activity of this up-regulated system is inhibited in vivo by persistent morphine exposure. As a result, the up-regulated G-protein/cAMP system leads to physiological and behavioral consequences, i.e., aspects of withdrawal, only after administration of opiate receptor antagonists reverses the ongoing inhibitory influence of the endogenous morphine.

The parallel between withdrawal behavior and LC neuronal activity suggests that activation of $\mathrm{LC}$ neurons plays a role in mediating aspects of the opiate abstinence syndrome. This is consistent with a number of studies that demonstrate a relationship between opiate abstinence signs and LC firing rates. First, electrical stimulation of the LC in nonhuman primates produces behaviors similar to those observed during opiate withdrawal (Grant et al., 1988). Second, local administration of opiate receptor antagonists directly into the LC of opiate-dependent animals increases LC firing rates (Aghajanian, 1978)

Figure 2. Time course of adenylate cyclase and cAMP-dependent protein kinase activities during opiate withdrawal. Rats were treated with morphine for $5 \mathrm{~d}$ and withdrawal was precipitated on day 6 by naltrexone administration. Animals were killed without the initial naltrexone injection, or $20 \mathrm{~min}, 1 \mathrm{hr}$, or $6 \mathrm{hr}$ later. Other animals received a second naltrexone injection at $6 \mathrm{hr}$ and were killed at $24 \mathrm{hr}$; still others received second and third naltrexone injections at 6 and $24 \mathrm{hr}$ and were killed at $72 \mathrm{hr}$. LC nuclei were isolated from control and withdrawing animals and adenylate cyclase activity $(A)$, and particulate $(B, t o p)$ and soluble $(B$, bottom) cAMP-dependent protein kinase activity, were assayed in LC subcellular fractions, as described in Materials and Methods. The data were calculated as mean percent change from control \pm SEM and represent the results of 4-12 control and morphine-treated animals for each time point. The data for adenylate cyclase represent forskolin-stimulated conditions; similar results were seen under basal conditions. For each enzyme determination, levels were significantly elevated above control in dependent animals (no naltrexone administration) and after $20 \mathrm{~min}$ and $1 \mathrm{hr}$ of withdrawal ( $p<0.05$ by $\chi^{2}$ test); levels were not different from control after 6,24 , and $72 \mathrm{hr}$ of withdrawal. 
Figure 3. Time course of G-protein ADP-ribosylation during opiate withdrawal. Rats were treated with morphine for $5 \mathrm{~d}$ and withdrawal was precipitated on day 6 by naltrexone administration. Animals were killed without the initial naltrexone injection, or 1 or $6 \mathrm{hr}$ later. Other animals received a second naltrexone injection at $6 \mathrm{hr}$ and were killed at $24 \mathrm{hr}$; still others received second and third naltrexone injections at 6 and $24 \mathrm{hr}$ and were killed at $72 \mathrm{hr}$. LC nuclei were isolated from control and withdrawing animals and levels of pertussis toxin-mediated ADPribosylation of $\mathrm{G}_{\mathrm{i} \alpha}$ and $\mathrm{G}_{\mathrm{o} \alpha}$ were assayed, as described in Materials and Methods. Top, Representative autoradiograms showing levels of G-protein ADP-ribosylation at the various time points studied. Ctr, Control; Dep, dependent animals without naltrexone administration; $1 \mathrm{hr}, 6 \mathrm{hr}, 24 \mathrm{hr}$, and $72 \mathrm{hr}$, times after naltrexone administration(s). 41 and $39 \mathrm{kD}$ refer to ADPribosylated $G_{i \mathrm{i}}$ and $G_{\alpha x}$, respectively (see Nestler et al., 1989). Bottom, Levels of G-protein ADP-ribosylation quantitated with a Betagen Betascope analyzer or by counting excised bands by liquid scintillation. The data were calculated as mean percent change from control \pm SEM and represent the results of 4-7 control and morphine-treated animals for each time point. The data shown reflect values for $\mathrm{G}_{\mathrm{i} \alpha}$ plus $\mathrm{G}_{\mathrm{o} \alpha}$; analysis of each protein individually yielded equivalent results (not shown). G-protein levels were significantly elevated above control in dependent animals (no naltrexone administration) and after 1 hr of withdrawal $\left(p<0.05\right.$ by $\chi^{2}$ test $)$; levels were not different from control after 6,24 , and $72 \mathrm{hr}$ of withdrawal.
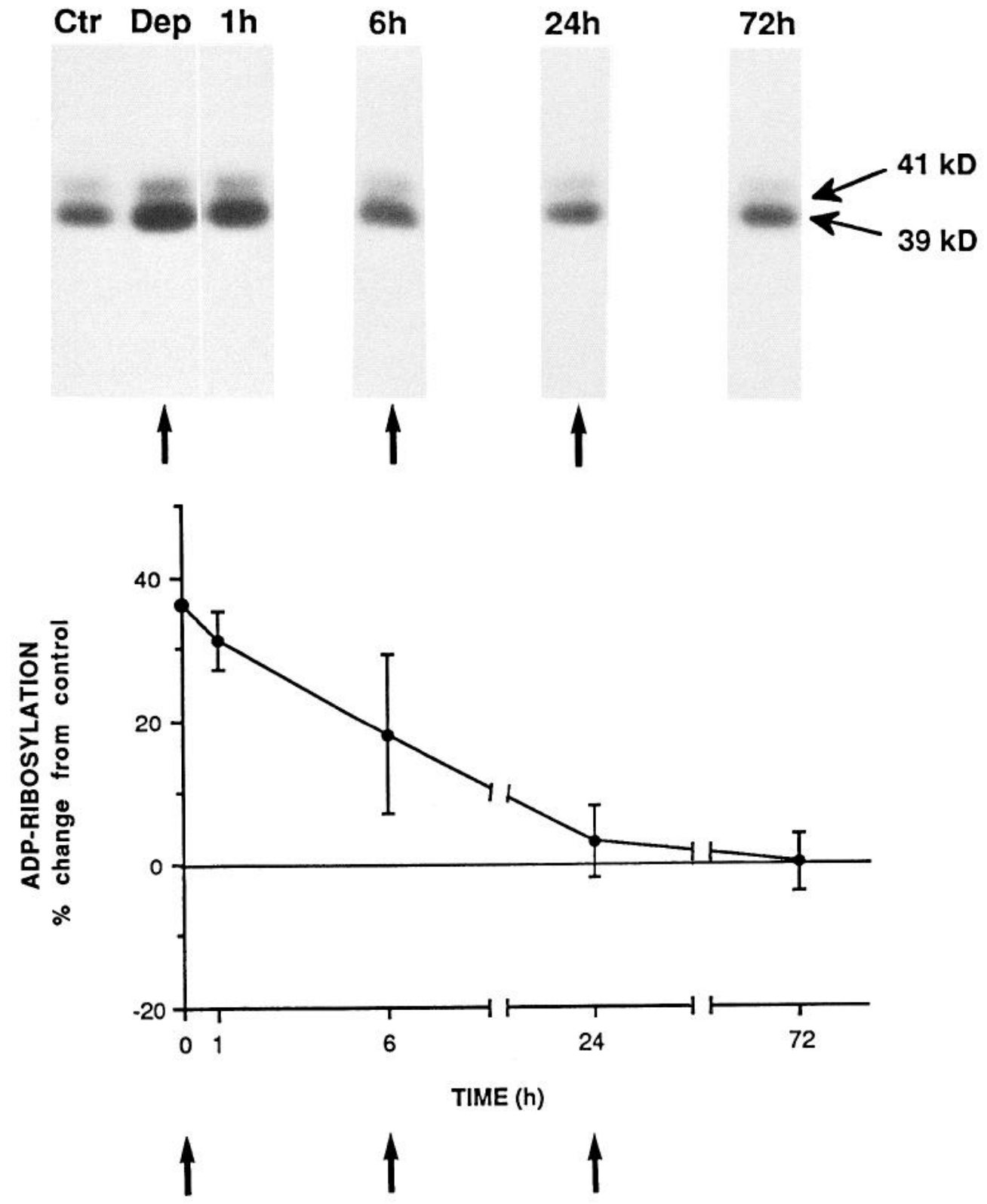

Naltrexone and elicits a number of withdrawal-like behaviors (Esposito et al., 1987). Third, pharmacological blockade of LC neuronal activity, for example, by local infusion of the $\alpha_{2}$-adrenergic agonist clonidine directly into the LC (see Aghajanian, 1978), blocks some of the behavioral signs of antagonist-precipitated opiate withdrawal in rats (Taylor et al., 1988). Studies with systemic clonidine provide further support for a role of the LC in mediating aspects of opiate withdrawal. Clonidine administration suppresses both the increased LC unit activity seen during opiate withdrawal in animals and the severity of opiate withdrawal symptoms in animals and humans (see Tseng et al., 1975; Aghajanian, 1978; Gold et al., 1978; Redmond and Krystal, 1984; Taylor et al., 1988). Moreover, an increased turnover of norepinephrine in cerebral cortex during opiate withdrawal, which presumably reflects increased LC neuronal activity under these conditions, has been shown to be reversed by clonidine
(Zigun et al., 1981; DiStefano and Brown, 1985). However, it is important to note that other sites in the CNS in addition to the LC, for example, adrenergic neurons elsewhere in the brain, amygdaloid neurons, and dorsal root ganglion/dorsal horn neurons, are also likely to play important roles in mediating aspects of opiate withdrawal and the effects of systemic clonidine on withdrawal (see Franz et al., 1982; Britton et al., 1984; Freedman and Aghajanian, 1985; Crain et al., 1987).

The decline seen in withdrawal behavior and LC unit activity over the course of this experiment was not due to a persisting effect of morphine, as repeated injections of naltrexone had no effect on either measure. The time courses described in this study, therefore, provide information, for the first time, about the complete reversal or "resetting" of the intrinsic processes in the brain that underlie opiate dependence. The results indicate that $72 \mathrm{hr}$ is required for the complete reversal of these 
processes during antagonist-induced opiate withdrawal. In contrast, preliminary observations indicate that a much longer period of time is required for complete reversal of these processes during spontaneous opiate withdrawal. Thus, when the 2 most recent morphine pellets were removed on day 6 and naltrexone was administered for the first time $72 \mathrm{hr}$ later, behavioral measures of withdrawal were $\sim 75 \%$ of those seen when naltrexone was first administered on day 6 . Similar relative degrecs of withdrawal activation of LC neurons were observed under these 2 conditions. One likely reason for the slower spontaneous withdrawal is the very long half-life of morphine in the brain (see Misra, 1978). It is also possible that low levels of morphine, absorbed from the remaining pellets, may have contributed to sustained dependence, although such absorption has been shown to be virtually complete within 3-4 d after implantation (Blasig et al., 1973). In addition, it is conceivable that the antagonist by itself could accelerate reversal of the changes underlying opiate dependence. For example, it has been found recently that the degree of opiate dependence in monkeys following chronic morphine treatment (assessed by the severity of behavioral withdrawal) can be dramatically decreased by the intermittent administration of low doses of naloxone during the treatment period (Krystal et al., 1989).

A central question raised by these studies is: What role does the up-regulated G-protein/cAMP system observed in the LC play in mediating the withdrawal activation of these neurons? The results of the present study, together with those of a number of previous studies, indicate that this up-regulated intracellular messenger system could contribute to the activation of the LC seen during early stages of opiate withdrawal. Thus, since opiates are known to inhibit LC neurons acutely (see beginning of article), the up-regulated cAMP system observed in opiate-dependent animals could represent a homeostatic response to persistent opiate inhibition of the cells. According to this view, the concurrent presence of morphine and the up-regulated cAMP system in opiate-dependent animals would result in LC firing rates close to control levels. When the morphine is "withdrawn" abruptly by administration of naltrexone, the up-regulated cAMP system, unopposed by morphine, would increase the activity of LC neurons. This model, which is similar to one proposed previously based on studies of cultured neuroblastoma $\times$ glioma cells (Sharma et al., 1975), is supported by several lines of evidence. cAMP and agents that act through increased levels of cAMP are known to excite LC neurons (North et al., 1987; Wang and Aghajanian, 1987), an effect shown recently to be mediated through cAMP-dependent protein kinase (Wang and Aghajanian, 1990). Moreover, in the present study, the time course by which components of the cAMP system recover during opiate withdrawal follows the early, rapid phase of withdrawal recovery during which time LC neuronal firing rates decrease from about 7 to $3.5 \mathrm{~Hz}$. Still further evidence for an up-regulated cAMP system contributing to opiate withdrawal are the observations that high systemic doses of phosphodiesterase inhibitors produce a morphine withdrawal-like syndrome in normal rats (Collier et al., 1981) and potentiate opiate antagonist discrimination in morphine-dependent rats (Holtzman, 1989). In addition, we have found that lower doses of phosphodiesterase inhibitors potentiate the behavioral abstinence syndrome and withdrawal activation of LC neurons in opiate-dependent rats (unpublished observations). It is possible that these effects of phosphodiesterase inhibitors are mediated in part at the level of the LC. It is interesting to note in this regard that a role for an up-regulated
cAMP system in mediating aspects of opiate dependence may not be limited to the LC, since increases in adenylate cyclase, and in some cases in CAMP-dependent protein kinase, in response to chronic opiate treatment have been observed in dorsal root ganglion/spinal cord explants (Makman et al., 1988) and in some other opiate-responsive brain regions (Nestler et al., 1990, and unpublished observations).

In contrast to the early stages of withdrawal, the up-regulated cAMP system cannot account for the sustained activation of LC neurons and withdrawal symptoms seen during later stages of withdrawal. Rather, these later signs of withdrawal could be due to various MARPPs known to be increased in opiate-dependent animals (Guitart and Nestler, 1989), to other intracellular messenger systems in the $\mathrm{LC}$, and/or to various extrinsic inputs to the LC.

The findings that withdrawal activation of $\mathrm{LC}$ neurons is not observed in isolated slice preparations (Andrade et al., 1983; Christie et al., 1987) and that withdrawal activation observed in vivo is blocked by lesions of the paragigantocellularis (Rasmussen and Aghajanian, 1989), which provides a major excitatory input to the LC (Ennis and Aston-Jones, 1988), indicate that intact synaptic connections are required for withdrawal activation of the LC. In view of recent studies showing a dramatic induction of c-fos, a nuclcar transcription factor that provides a measure of in vivo neuronal activity (see Sagar et al., 1988), in the LC during opiate withdrawal, but no increase in c-fos in the paragigantocellularis (Hayward et al., 1990), it is possible that the withdrawal activation of the $\mathrm{LC}$ seen in vivo is due largely to cell bodies and/or nerve terminals in the LC that are supersensitive to a relatively constant input from the paragigantocellularis. Indeed, as discussed above, the up-regulated cAMP system observed in the $\mathrm{LC}$ in response to chronic opiates provides a possible biochemical basis for such supersensitivity. Moreover, one of the MARPPs found to be induced in the LC in response to chronic opiates, MARPP-58, has been shown recently to be tyrosine hydroxylase (Guitart et al., 1990). Such up-regulation of tyrosine hydroxylase, which occurs at the messenger RNA and protein level, is further evidence for an increased "intrinsic excitability" of LC neurons during opiate dependence (Guitart et al., 1990).

Clearly, further studies are needed to test the validity of these and many alternative hypotheses. For example, studies should be performed aimed at direct confirmation of a possible role for an up-regulated G-protein/cAMP system in mediating the early stages of the withdrawal activation of LC neurons. Nevertheless, this report illustrates the power of studies of anatomically welldefined, relatively homogeneous brain regions, such as the $\mathrm{LC}$, in which biochemical data can be understood within a physiological and behavioral context. Through further characterization of the biochemical responses of $L C$ neurons to opiates, a better understanding will be achieved of the mechanisms underlying opiate addiction at the molecular level.

\section{References}

Abercrombie ED, Levine ES, Jacobs BL (1988) Microinjected morphine suppresses the activity of locus coeruleus noradrenergic neurons in freely moving cats. Neurosci Lett $86: 334-338$.

Aceto MD, Dewey WL, Portoghese PS, Takemori AE (1986) Effects of b-flunaltrexamine (b-FNA) on morphine dependence in rats and monkeys. Eur J Pharmacol 123:387-393.

Aghajanian GK (1978) Tolerance of locus coeruleus neurones to morphine and suppression of withdrawal response by clonidine. Nature $267: 186-188$. 
Aghajanian GK, Wang Y-Y (1986) Pertussis toxin blocks the outward currents evoked by opiate and $\alpha 2$-agonists in locus coeruleus neurons. Brain Res 371:390-394.

Aghajanian GK, Wang Y-Y (1987) Common alpha-2 and opiate effector mechanisms in the locus coeruleus: intracellular studies in brain slices. Neuropharmacology 26:789-800.

Aghajanian GK, Cedarbaum JM, Wang RY (1977) Evidence for norepinephrine-mediated collateral inhibition of locus coeruleus neurons. Brain Res 136:570-577.

Andrade R, VanderMaelen CP, Aghajanian GK (1983) Morphine tolerance and dependence in the locus coeruleus: single cell studies in brain slices. Eur J Pharmacol 91:161-169.

Beitner DB, Duman RS, Nestler EJ (1989) A novel action of morphine in the rat locus coeruleus: persistent decrease in adenylate cyclase. Mol Pharmacol 35:559-564.

Bird SJ, Kuhar MJ (1977) Iontophoretic application of opiates to the locus coeruleus. Brain Res 122:523-533.

Blasig J, Herz A, Reinhold K, Zieglgansberger S (1973) Development of physical dependence on morphine in respect to time and dosage and quantification of the precipitated withdrawal syndrome in rats. Psychopharmacologia 33:19-38.

Britton KT, Svensson T, Schwartz J, Bloom FE, Koob GF (1984) Dorsal noradrenergic bundle lesions fail to alter opiate withdrawal or suppression of opiate withdrawal by clonidine. Life Sci 34:133-139.

Christie MJ, Williams JT, North RA (1987) Cellular mechanisms of opioid tolerance: studies in single brain neurons. Mol Pharmacol 32: 633-638.

Collier HOJ, Cuthbert NJ, Francis DL (1981) Character and meaning of quasi-morphine withdrawal phenomena elicited by methylxanthines. Fed Proc 40:1513-1518.

Crain SM, Crain B, Makman MH (1987) Pertussis toxin blocks depressant effects of opioid, monoaminergic and muscarinic agonists on dorsal-horn network responses in spinal cord-ganglion cultures. Brain Res 400:185-190.

Dahlstrom A, Fuxe K (1965) Evidence for the existence of monoamine-containing neurons in the central nervous system. I. Demonstration of monoamines in the cell bodies of brainstem neurons. Acta Physiol Scand 232 (Suppl): 1-55.

Danks JA, Tortella FC, Long JB, Bykov V, Jacobson AE, Rice KC, Holaday IW, Rothman RB (1988) Chronic administration of morphine and naltrexone up-regulate $\left[{ }^{3} \mathrm{H}\right]-\left[\mathrm{D}-\mathrm{Ala}^{2}, \mathrm{D}-\mathrm{Leu}^{5}\right]$ enkephalin binding sites by different mechanisms. Neuropharmacology 27:965974.

DiStefano PS, Brown OM (1985) Biochemical correlates of morphine withdrawal. 2. Effects of clonidine. J Pharmacol Exp Ther 233:339344.

Duman RS, Tallman JF, Nestler EJ (1988) Acute and chronic opiateregulation of adenylate cyclase in brain: specific effects in locus coeruleus. J Pharmacol Exp Ther 246:1033-1039.

Ennis M, Aston-Jones G (1988) Activation of locus coeruleus from nucleus paragigantocellularis: a new excitatory amino acid pathway in brain. J Neurosci 8:3644-3657.

Esposito E, Kruszewska A, Ossowska G, Samanin R (1987) Noradrenergic and behavioral effects of naloxone injected in the locus coeruleus of morphine-dependent rats and their control by clonidine. Psychopharmacology 93:393-396.

Foote SL, Bloom FE, $\Lambda$ ston-Jones G (1983) Nucleus locus coeruleus: new evidence of anatomical and physiological specificity. Physiol Rev 63:844-914.

Franz DN, Hare BD, McCloseky KL (1982) Spinal sympathetic neurons: possible sites of opiate withdrawal suppression by clonidine. Science 215:1643-1645.

Freedman JE, Aghajanian GK (1985) Opiate and alpha-2-adrenoceptor responses of rat amygdaloid neurons: co-localization and interactions during withdrawal. J Neurosci 5:3016-3024.

Gold MS, Redmond DE Jr, Kleber HD (1978) Clonidine blocks acute opiate-withdrawal symptoms. Lancet 2:599-602.

Grant SJ, Huang YH, Redmond DE Jr. (1988) Rehavior of monkeys during opiate withdrawal and locus coeruleus stimulation. Pharmacol Biochem Behav 30:13-19.

Guitart X, Nestler EJ (1989) Identification of morphine and cyclic AMP-regulated phosphoproteins (MARPPs) in the locus coeruleus and other regions of rat brain. Regulation by acute and chronic morphine. J Neurosci 9:4371-4387.

Guitart X, Nestler EJ (1990) Identification of MARPP-14-20, morphine- and cyclic AMP-regulated phosphoproteins of $14-20 \mathrm{kD}$, as myelin basic proteins. Evidence for their acute and chronic regulation by morphine in rat brain. Brain Res 516:57-65.

Guitart X, Hayward MD, Nisenbaum LK, Beitner DB, Haycock JW, Nestler EJ (1990) Identification of MARPP-58, a morphine- and cyclic AMP-regulated phosphoprotein of $58 \mathrm{kDa}$, as tyrosine hydroxylase: evidence for regulation of its expression by chronic morphine in the rat locus coeruleus. J Neurosci (in press).

Hayward MD, Duman RS, Nestler EJ (1990) Induction of the c-fos proto-oncogene during opiate withdrawal in the locus coeruleus and other regions of rat brain. Brain Res (in press).

Himmelsbach CK, Gerlach GH, Stanton EJ (1935) A method for testing addiction, tolerance, and abstinence in the rat. J Pharmacol Exp Ther 53:179-188.

Holtzman SG (1989) Phosphodiesterase inhibitors potentiate opiateantagonist discrimination by morphine-dependent rats. Pharmacol Biochem Behav 33:875-879.

Korf J, Bunney BS, Aghajanian GK (1974) Noradrenergic neurons: morphine inhibition of spontaneous activity. Eur J Pharmacol 25 : 165-169.

Krystal JH, Walker MW, Heninger GR (1989) Intermittent naloxone attenuates the development of physical dependence on methadone in rhesus monkeys. Eur J Pharmacol 160:331-338.

Lee MC, Wagner HN Jr, Tanada S, Frost JJ, Bice AN, Dannals RF (1988) Duration of occupancy of opiate receptors by naltrexone. $J$ Nucl Med 29:1207-1211.

Loh HH, Tao P-L, Smith AP (1988) Invited review: role of receptor regulation in opioid tolerance mechanisms. Synapse 2:457-462.

Lowry OH, Rosebrough NJ, Farr AL, Randall RJ (1951) Protein measurement with the folin phenol reagent. J Biol Chem 193:265275.

Makman MH, Dvorkin B, Crain SM (1988) Modulation of adenylate cyclase activity of mouse spinal cord-ganglion explants by opioids, serotonin and pertussis toxin. Brain Res 445:303-313.

Misra AL (1978) Metabolism and opiates. In: Factors affecting the action of narcotics (Adler ML, Manara L, Samanin R, eds), pp 297 343. New York: Raven.

Nestler EJ (1990) Adaptive changes in signal transduction systems: Molecular mechanisms of opiate addiction in the rat locus coeruleus. In 13th International Conference on Membrane Biology (Ritchie JM, Magistretti PJ, eds). New York: Elsevier (in press).

Nestler EJ, Tallman JF (1988) Chronic morphine treatment increases cyclic AMP-dependent protein kinase activity in the rat locus coeruleus. Mol Pharmacol 33:127-132.

Nestler EJ, Erdos JJ, Terwilliger R, Duman RS, Tallman JF (1989) Regulation of G-proteins by chronic morphine in the rat locus coeruleus. Brain Res 476:230-239.

Nestler EJ, Beitner DB, Hayward M, Sevarino KA, Terwilliger R (1990) A general role for adaptations in G-proteins and the cyclic AMP system in mediating the chronic actions of morphine and cocaine on brain function. Soc Neurosci Abs 16 (in press).

North RA, Williams JT, Suprenant A, Christie MJ (1987) Mu and delta receptors belong to a family of receptors that are coupled to potassium channels. Proc Natl Acad Sci USA 84:5487-5491.

Rasmussen K, Aghajanian GK (1989) Withdrawal-induced activation of locus coeruleus neurons in opiate-dependent rats: attenuation by lesions of the nucleus paragigantocellularis. Brain Res 505:346-350.

Rasmussen K, Jacobs BL (1985) Locus coeruleus unit activity in freely moving cats is increased following systemic morphine administration. Brain Res 344:240-248.

Redmond DE Jr, Krystal JH (1984) Multiple mechanisms of withdrawal from opioid drugs. Annu Rev Neurosci 7:443-478.

Sagar SM, Sharp, FR, Curran T (1988) Expression of c-fos protein in brain: metabolic mapping at the cellular level. Science 240:13281331.

Sharma SK, Klee WA, Nirenberg M (1975) Dual regulation of adenylate cyclase accounts for narcotic dependence and tolerance. Proc Natl Acad Sci USA 72:3092-3096.

Taylor JR, Elsworth ID, Garcia EJ, Grant SJ, Roth RH, Redmond DE $\mathrm{Jr}$ (1988) Clonidine infusion into the locus coeruleus attenuates behavioral and neurochemical changes associated with naloxone-precipitated withdrawal. Psychopharmacology 96:121-134.

Tempel A, Zukin RS (1987) Neuroanatomical patterns of the $\mu, \delta$, and $\kappa$ opioid receptors of rat brain as determined by quantitative in vitro autoradiography. Proc Natl Acad Sci USA 84:4308-4312.

Tseng L-F, Loh HH, Wei ET (1975) Effects of clonidine on morphine withdrawal signs in the rat. Eur J Pharmacol 30:93-99. 
Valentino RJ, Wehby RG (1988) Morphine effects on locus coeruleus neurons are dependent on the state of arousal and availability of external stimuli: studies in anesthetized and unanesthetized rats. J Pharmacol Exp Ther 244:1178-1186.

Valentino RJ, Wehby RG (1989) Locus coeruleus discharge characteristics of morphine-dependent rats: effects of naltrexone. Brain Res 488:126-134.

Wang Y-Y, Aghajanian GK (1987) Excitation of locus coeruleus neurons by an adenosine $3^{\prime}, 5^{\prime}$-cyclic monophosphate-activated inward current: extracellular and intracellular studies in rat brain slices. Synapse 1:481-487.

Wang Y-Y, Aghajanian GK (1990) Excitation of locus coeruleus neu- rons by vasoactive intestinal peptide: Role of cAMP and protein kinase A. J Neurosci (in press).

Way EL, Loh HH, Shen F-H (1969) Simultaneous quantitative assessment of morphine tolerance and physical dependence. J Pharmacol Exp Ther 167:1-8.

Wei E (1973) Assessment of precipitated abstinence in morphinedependent rats. Psychopharmacologia (Berl) 28:35-44.

Zigun JR, Bannon MJ, Roth RH (1981) Comparison of two $\alpha$-noradrenergic agonists (clonidine and guanfacine) on norepinephrine turnover in the cortex of rats during morphine abstinence. Eur J Pharmacol 70:565-570. 